\title{
De Dicto Cognitive Reason Contextualism
}

\author{
Saleh Afroogh
}

What does it mean to say that an agent has a reason to do a certain action? Does it mean that she would desire to do the action, or that there is some external consideration, which she ought to follow? Or is there a third alternative? The debate between Humean affective (i.e., desire-based) and classical Kantian cognitive theories has seemingly ended up in a theoretical standoff, and so most of the contributors have recently focused on the conative attitude of motivation - either preceded by affective or cognitive attitudes. Accordingly, they contend that an agent has a reason to $\phi$ only if, on some occasions, she would be motivated to $\phi$ : call this Conative Reason Internalism.

I argue, first, that even the most qualified version of this weak conative condition obtains only contingently. Secondly, that a cognitive contextual attitude, derived from the agent's capacity of Reasons-Understanding, necessarily obtains. Therefore, necessarily, if an agent has a reason to $\phi$, it follows that, were she contextually rational, she would make evaluative sense out of the propositional content of $\phi$-ing or would understand why $\phi$-ing is considered as a right action in the relevant context: I call this De Dicto Cognitive Reason Contextualism.

Keywords: normative reason, internalism, externalism, contextualism

\section{Introduction}

Ever since Williams (1979) qualified a Humean affective (i.e., desire-based) Theory of Reason and cast doubt on the plausibility of the classical externalist account of practical reasoning, highlighting instead the explanatory dimension required for every reason for action, most practical reasoning theorists (see, for instance, Korsgaard 1986; Smith 1994; Velleman 2000; Joyce 2001; Darwall 1983; McDowell 1995; Brandt 1979; Nagel 1970; A) have been convinced that a kind of conative attitude, viz. motivation, necessarily obtains in the definition of normative reason. This necessary condition is widely supposed to be a weak counterfactual conative attitude (i.e., counterfactual motivation), and thus any affective Humean theory would be compatible with this condition only in a non-substantive sense (Schroeder 2007). However, as we will see, the most qualified substantive version of the weak counterfactual conativism obtains only contingently. As the first goal of this paper, I argue that irrespective of whether they are treated objectively or subjectively, the purported counterfactuals are either unnecessary or insufficient; furthermore, even a more commonsensical and qualified account of Contextual Conative Internalism, whether in its agentic or austere sense, does not obtain necessarily; all face counterexamples. 
As the second goal, I aim to establish an alternative theory of normative reason on the basis of the agent's cognitive attitudes (i.e., neither the affective nor the conative attitudes). It seems that the vulnerability of different versions of conative internalism originates from a basic supposition about the agent's capacity to be motivated by reasons (which I call the capacity of Beingmotivated-by-reasons), which itself seems only contingently true of the concept of an agent. I therefore switch to a more basic cognitive grounding which every human agent necessarily and by nature would exemplify - i.e., the capacity to understand reasons (what I call the capacity of Reasons-Understanding). I hope to show how a cognitive contextual theory based on the capacity of Reasons-Understanding, while fully independent of an agent's affective (e.g., desires/likes) or conative (e.g., motivations) attitudes, can accommodate all the counterexamples, and satisfy the major challenges observed in the debate between classical internalism and externalism. I call this position Cognitive Reason Contextualism and, finally, I show that regarding its de dicto sense, it has the additional privilege of being compatible with de re reason universalism as well. If my arguments work, it makes sense to adopt De Dicto Cognitive Reason Contextualism as the correct position in the debate.

My discussion proceeds as follows. In Section 1, I contemplate two things. First, the contingent relation between explanatory, motivating, and "normative" reasons; secondly, the bijective function of the Humean Theory of Reason. In section 2, I show that the Williamsian Theory of Reason can best be captured by an injective only (non-surjective) function from an agent's normative reasons to her actual affective attitudes. In section 3, I elaborate on some major challenges against both classical internalism and externalism, which guide to the weak theory of Conative Reason Internalism. In section 4, I classify the extant accounts of Conative Reason Internalism into three idealized versions and one commonsensical contextual version. Then, I demonstrate their contingent nature through some intuitive counterexamples. In section 5, I first qualify Contextual Conative Internalism by couching it in an austere contextual sense; then I refute it by reference to another intuitive example. In section 6, I argue that it is not helpful to apply further qualification to Conative Internalism (which is based on the seemingly contingent capacity of Being-motivated-by-reasons), and I switch instead to the necessary capacity of Reasonsunderstanding; in this section, I elaborate on Cognitive Reason Contextualism and its advantages. In section 7, De Dicto Cognitive Reason Contextualism is shown to be the version which it makes most sense to adopt. Section 8 concludes.

\section{Practical reasoning and Humean Actual Affectivivsm}

You have just started reading this paper, and you are reading it from left to right, following the conventional linguistic norm which says English text ought to be read from left to right. ${ }^{1}$ This norm is an external consideration, which is independent of any given agent's desires; however, it

\footnotetext{
1. This implies a meaningful relation between the normativity of language and the normative reason for action, however, in this paper I do not follow up on this idea. For some related discussions, see Hattiangadi 2007, Gibbard 2012 .
} 
also happens to be your motivating reason (i.e., the operative reason in your mind, which might be not present yet conscious) $)^{2}$ when you are reading it from left to right. Such a rule figures in the best explanation for your action as well, and it seems that all three kinds of reasons (i.e., normative, motivating, and explanatory reasons) are co-referential. However, a claim is also made that the normative reason is only contingently coincident with the external norm. According to the Humean Theory of Reason (henceforth, HTR) ${ }^{3}$, as well as the Williamsian Theory of Reason (hereafter, WTR), you have a normative reason to follow the maxim "read English text from left to right" only if you want (have a desire) to do so. ${ }^{4}$ Otherwise, if you wanted to read it inversely, whether pointlessly ${ }^{5}$ or out of an imaginary belief, ${ }^{6}$ you would have a "normative" reason not to follow this conventional norm (Afroogh 2019). ${ }^{7}$

Suppose you turn your copy of this paper over (assuming you are not reading online). If you are then asked why you did not turn it over with your left hand, you might respond with a baffled "Pardon me?"; or pehaps you would say "It just happened pointlessly"; or maybe "Because it was easier for me as a right-handed person." The two former responses show that there was no operative considered belief in your mind relevant to the action; that is, no motivating reason for your turning over the paper with your right hand in these cases. But the latter response indicates the presence of a motivating reason (i.e., "it was easier for me"), which is your basic explanatory reason as well. Few people, however, would go beyond this to mention more basic biological or genetic explanations underlying hand dominance as a reason for her act of "turning it over with her right hand." The unconscious biological or genetic facts are not motivating reasons, though they may be considered as underlying unconscious explanatory reasons. Notice that the motivating and unconscious explanatory reasons here are both operative, yet not the same.

However, on some occasions one falls into introspective confabulations about the motivating reason. Suppose that you are sitting on the right-hand-side seat of a double seat table while you are reading, and someone asks why you are not sitting on the left-hand-side seat? You might reply "I chose the right-hand-side seat because it looked more accessible (nearer) to me from the left-side one," or "Because the right-hand-side seat looks more comfortable," whereas in fact both seats are equally close and equally comfortable; this might show that you are influenced by some basic unconscious cause, perhaps hand dominance or a habit bias, and you are confabulating about the reasons actually operative in your mind. The unconscious cause, as an underlying explanatory reason, might ease your choice of the right-hand-side seat; however, it certainly

\footnotetext{
2 . This excludes unconscious reasons, which are fully unkown for the agents.

${ }^{3}$. I am not going to follow up any historical explication here, and by HTR, I just follow the common conseption about Humean practical reason theory.

${ }^{4}$. For Williams's transition from biconditional necessity to the material condition, see first Williams 1979, p. 101, and then his 1989 , p. 35.

${ }^{5}$. I come back to this notion in section 3 .

${ }^{6}$. Imaginary belief plays a central role in Williamsian deliberations; however, his theory of internal reason is constrained by dersires not by belief (including imaginary ones).

${ }^{7}$. For still more implausible cases which are considered as reasons by Williams, see his 1989, p. 37, in which he allows some paradoxical desires to be reason-makers in self-deception cases.
} 
doesn't make it physically nearer or better upholstered. Motivating and explanatory reasons are not always convergent (Hirstein 2009).

That being said, according to HTR, all reasons ought to be defined in terms of our affective attitudes (i.e., passions or desires), no matter when, where, and how the action is done or supposed to be done, and no matter why, in its justificatory sense, the action should be done. As Hume remarked, "Reason is, and ought only to be the slave of the passions and can never pretend to any other office than to serve and obey them" (Hume 1739/40); thus the normativity of reason is to be reduced semantically (or sacrificed) to the explanatory power of the desire for the action, in response to the question why, posed in its explanatory sense. A normative reason for action neither necessarily represents some norm nor is actually equivalent to some unconscious explanatory reason (underlying cause); however, it may be co-referential with some norm or some explanatory reason, but contingently so. Humean normative reason merely aims to be reducible to the motivating reason, and so you are equally justified to do (or not to do) any course of action, provided only that you want to do (or not to do) it.

The effective HTR can be best modeled by a bijective function (one-to-one correspondence) between the agent's normative reasons, or her best reasons, to her actual affective attitudes, or her strongest ones (Figure 1); its being a one-to-one correspondence thus implies an inverse function from the agent's actual affective attitudes to her normative reasons as well. However, it might be thought that HTR also bijectively maps an agent's normative reasons to her motivating reasons. I come back to this in section 3. Notice that if normative reasons ought to be mapped bijectively onto an agent's affective attitudes, HTR per se would not be a justificatory and plausible reason for non-Humeans, who are not passionate about it; as if it would justify the Humeans as long as they are passionate about it, no matter whether or not it is correct in fact. ${ }^{8}$

\section{Williamsian conditional affectivivsm: conjunctives vs. counterfactuals}

Williams qualified Humean affectivism in three ways: first, by rejecting the bijective function via a no-false-belief condition (which in turn leads to the neglected reason); secondly, by extending the codomain of the function (i.e., an agent's passions) such that it includes all kinds of affective attitudes (i.e., desire-likes); ${ }^{9}$ thirdly, by changing the biconditional relation between reason and desires (posited in 1979) to a necessary condition (in 1989). On these grounds, he attempted a

\footnotetext{
${ }^{8}$. Hume, famously, holds that it is impossible to derive an ought from an is. That is, he holds that it doesn't make sense to posit inferred evaluative terms (oughts) without the presence of some evaluative term among the premises from which they are inferred. Yet his slogan "reason [i.e., oughts] is, and ought only to be slave of the passion [defined in terms of desires]" itself includes a derivative ought inferred from an is (See Korsgard 1997). The same objection, with still stronger force, applies to Williams's account, who states "reasons not only ought to be defined or be governed by our affective attitudes, but they also ought to be excluded from effective false beliefs, and they ought to be included by effective neglected reason for action." Such oughts are constituents of Williamsian instrumental reason, and it seems that by no means can they be understood as hypothetical imperatives. They are intended as substantive (not even borderline instrumental) reasons for every agent, irrespective of their affective attitudes. Otherwise, if you treat similarly with the ought in the slogan, and define it in terms of passions, then it would be justificatory only for those who are passionate about it!
} 
normativization of Humean actual affective theory, so as to make it less implausible (Finlay 2009). We can set this position out as follows:

(1) Williamsian Conditional (i.e., conjunctive) Affective Internalism: An agent has a reason to $\phi$ only if she actually "has some desire the satisfaction of which will be served by his $\phi$ ing," in conjunction with the no-false-belief condition (Williams 1979).

However, it seems that Williams's condition, interpreted in a conjunctive sense, is strong. Consider the following case (Case 1), Philip wants to help a poor person, and on the basis of some evidence (such as her having a very old car or wearing used clothes) he comes to believe that his neighbor, Sarah, is poor, and decides to help her (at $\mathrm{T}_{1}$ ). In fact, though, she is the rich owner of a large company, and not poor at all. Then, though some malversation by her business manager, she goes bankrupt, and so becomes poor (at $\mathrm{T}_{2}$ ). Philip wanted to help Sarah as a poor person, and she is poor now; so it seems intuitive that he has still reason to help her as a poor person. But his practical reasoning is based on the false belief that his neighbor, Sarah, is poor at $\mathrm{T}_{1}$. The same story can be conceived for Williams's own example of a gin and tonic, with the same intuitive conclusion. If a third party stealthily changes the content of a bottle from petrol to gin and tonic, then it seems that even Williams has no problem conceiving her drinking as reasonable action, even though it is based on a false belief that the bottle was full of gin and tonic.

So, Sarah's being poor, though true by luck, is enough for Philip to have reason to help her as a poor person. Yet Philip doesn't know that she is poor (for his belief is true by luck), and he doesn't know that he has a reason to help her; however, he still has a reason to help her. Having a reason, in spite of knowing having reason, allows to true by luck situations. It seems that we should move, then, to a qualified interpretation of Williams's theory, which I referred to by WTR:

(2) Williamsian Counterfactual Affective Internalism (WTR): If an agent has a reason to $\phi$ then, necessarily, if she deliberates in the absence of false beliefs, she would desire to $\phi^{10}$

WTR can accommodate Case 1: had he known the whole story, Philip would still desire to help Sarah, now as a poor person, and so he has a reason to do so.

The normativity which is intended by the counterfactual condition is neither too subjective, like Hume's "normativity" which is supposed to be fully reduced to motivating reasons (and so allows the possibility of effective false beliefs which, if they had been known, would change the agent's mind); nor is it as objective as the actual no-false-belief condition (which excludes Case 1). ${ }^{11}$ The Williamsian counterfactual theory blocks the full involvement of either actual subjective desires or actual objective data; he defines normative reason on the basis of the desirability of relevant informations if were known.

\footnotetext{
${ }^{10}$. Notice that the deliberation is not necessriliy a correct or formal one (Williams 1995)

${ }^{11}$. As we will see in section 4, this no effective-false-belief condition, in turn, leads only to close effective neglected reasons, and not to the idea that all neglected facts would be reason-makers.
} 
Williams normativized HTR by adding a no-false-belief counterfactual condition, and it seems that he thereby aimed to reduce the "normative" reasons to the normativized motivating reasons (Finlay, 2009). So, he turns the Humean bijective function to an injective only (nonsurjective) function from an agent's normative reasons to her actual affective attitudes (including desire-likes), which maps every affective attitude at most to one element in the domain of the agent's normative reasons set; this injective function allows there to be a normative reason which either is not paired to any element in the agent's affective attitudes (like in the effective false belief case) or is paired to some external element which is not in the agent's motivational set (as in the case of the neglected reason)(Figure 2); moreover, since it is not surjective, it is not the case that every affective attitude whatsoever is a reason-maker. Williams (1971) states this explicitly, and it might imply that WTR bijectively maps an agent's normative reasons to her normativized motivating reasons as well. I will explore this further under the heading of True Pointless Actions in section 3 .

Figur 1: Humean bijective function

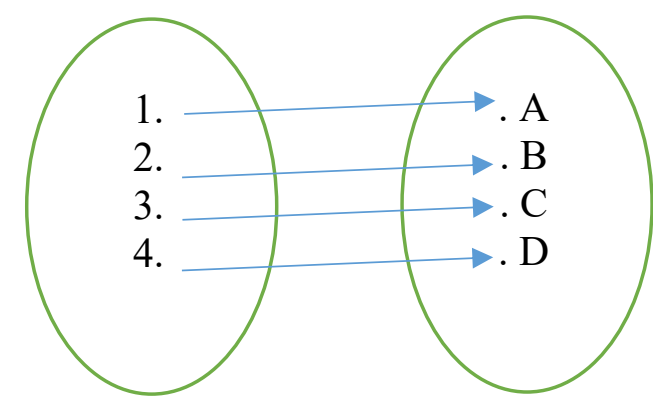

Normativ Reasons $\rightarrow$ Actual affective attitudes
Figure 2: Williamsian injective only (non-surjective) function

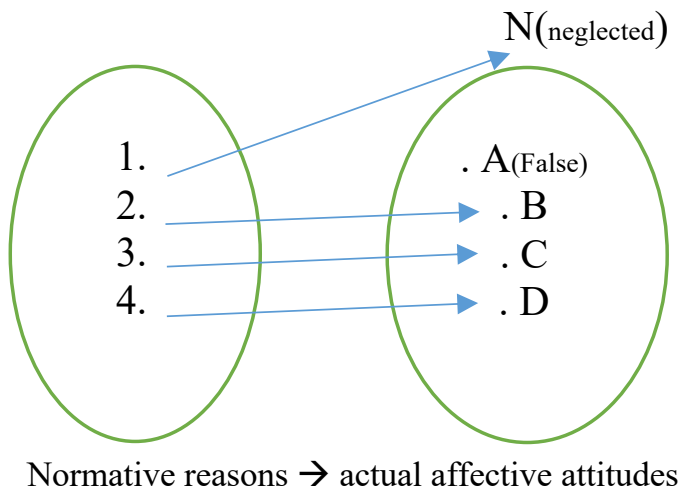

Kantians (as opposed to Humeans) and classical externalists (as opposed to Williamsian externalists) do not accept these reductionist strategies, and reject both the Humean bijective and Williamsian injective only functions. They take normative reasons to be entirely independent of an agent's affective attitudes. Thus, they believe that we are not justified to read an English text from left to right, no matter what the passions or desires say. Needless to say, nobody in the debate endorses the reduction of normative reasons to underlying unconscious explanatory reasons as well-adopting an unconscious cause as a practical reason is odd enough in itself. I will come back to this more than twice.

Williams proposes an argument to show the implausibility of putative external reasons. According to Williams (1989), first, "If something can be a reason for action, then it could be someone's reason for acting on a particular occasion, and it would then figure in an explanation of that action," and the explanation necessarily requires a kind of motivation to be at work: that is, there is a normative reason only if there is a conative attitude involved. Secondly, affective attitudes (desire-like attitudes) are the necessary constitutive, while cognitive attitudes are the contingent ones of the conative attitudes. If so, this issues in the bijective function from an agent's 
normative reasons to her actual affective attitudes. Then, given Williams's qualification conditions (like no-false-belief), the function turns into an injective only (non-surjective) function from an agent's normative reasons to her actual affective attitudes (including desire-likes).

However, the argument observed as question beging (see, Cohon 1986; Finlay 2009); and the second premise, i.e., the Humean Theory of Motivation, is highly controversial, and the validity of the argument (and consequently the conclusion) has been widely questioned (see, for instance, Nagel 1970, McDowell 1978, Darwall 1983). Finaly, some major challenges in the debate lead most recent practical reason theorists to reconcile on the first premise as the weak internal requirement for normative reasons - that is, schematic Conative Reason Internalism. I will elaborate on it in section 4.

\section{Some major challenges}

The Explanatory Challenge and Reason Universalism are two major challenges, which have convinced many reason theorists to modify their theories. These challenges, respectively, are related to justificatory (or normative) and explanatory dimensions of every normative reason. The former is usually thought to be problematic more for internalists, while the latter is largely considered only against externalists. Yet I doubt whether the implications of these problems can be so neatly circumscribed. It seems to me that each is problematic for both sides.

1. Reason Universalism, which also includes Moral Universalism and implies the moral Central Problem, is usually invoked against reason internalism; however, it casts doubt on reason externalism as well. If Reason Absolutism is right (i.e., wrong actions-whether morally, logically, or empirically wrong, etc.- - are wrong for every agent irrespective of her psychological attitudes), conjoining it with Reason Rationalism (i.e., an action is wrong only if there is a reason for the agent not to do it) entails an orthodox idea of Reason Universalism, which says all agents have the same reasons to not do the-morally, logically, empirically, etc.-wrong actions, no matter whether they are motivated by these reasons or not, and no matter whether they can make any sense of them or not. This therefore includes Moral Universalism, which can be inferred, similarly, from the conjunction of Moral Absolutism and Moral Rationalism (Finlay 2017).

Reason Universalism clearly poses a challenge for affective reason internalism, which cannot accommodate "true irrationality" (as in the case that the agent wants to read an English text from right to left) and true immorality (as in the apparent case of Hitler), (Korsgaard 1986). ${ }^{12}$ However, Reason Universalism, as the core idea of classical externalism, is not uncontroversial either. Consider a case in which you expect a young girl from a lost patriarchal tribe who is "not been properly brought up" to follow the rules of liberal democracy (here posited as the most rational and moral political system), instead of her conservative tribal system, or condemn her for

\footnotetext{
12. Notice that the true immoral case is different from true amoralist one, which I will mention it in section 6 . In the former, there is simply an immoral action, while, in the latter, an agent sincerely express that she believes in some moral code but she is not motivated to follow it.
} 
her thinking that she is not legally equal to her brother (McDowell 1995). It seems that it is you who has irrational expectations and who immorally condemns her, for it is not fair to expect her to understand what is very far from her context, or condemn her credence given that there is no defeater accessible to her in the context. Classical externalism, taken as a commitment to orthodox Reason Universalism, is subject to similar challenges as well.

2. Williams starts his classic argument with the Explanatory Challenge, which is sketched in terms of a psychological version of the principle of ought implies can. That is, the normative ought implies a psychological (affective) can. Accordingly, an agent has a reason for an action only if, at least on some occasions, she can be motivated towards that action: and it seems that external reason per se lacks the required motivational feature. Externalists, by contrast, resist the challenge by construing the principle in the physical (anti-psychological) sense of can. However, the appeal to physical possibility is weak, and fails to include a lot of intuitive cases (like the young girl in the tribe, for whom it would be physically possible to follow democratic ideas). ${ }^{13}$

The challenge seems to be problematic for affective internalism as well. Williams has reduced can, in the principle, to would (want): so for him, ought implies would. However, some woulds (like wishing or desiring to be omnipresent) imply cannot; that is, desire doesn't necessarily imply the possibility of the action. Therefore, according to Williams, there can be some oughts which cannot "then figure in an explanation of that action," even on some "particular occasions," due to the fact that those actions are not possible, neither here nor in any other possible world. And yet other desires, like "wanting to prove Goldbach's Conjecture," are controversial as regards their possibilty, and so don't necessarily imply can; it is unknown whether or not they can play an explanatory role even on "some occasions." Such a desire lacks the explanatory dimension (which is required for every normative reason), however, based on Williams (in 1989), as well as HTR, they are considered as reasons. WTR (in 1989) doesn't mention any condition which excludes such odd cases.

It might be said that "wishing to be omnipresent" is in a sense based on false belief, or at least entails some false beliefs, and so is not a reason-maker for Williams. The response is that, first, what is excluded by Williams is a desire which "is dependent on false belief" or a desire in which there is a false belief "in the relevance of $\phi$-ing to the satisfaction of D," neither of which necessarily obtains here. One may desire to be omnipresent just because one thinks "it would be exciting to be omnipresent" (a true belief), yet never consider how to become omnipresent, so there is no relevant false belief in satisfying the desire. "Becoming omnipresent," if it were possible, would definitely satisfy "wishing to be omnipresent" without any false beliefs at work. Such an objection could not be proposed against "wanting to prove Goldbach's Conjecture," because it is more clear that it is neither dependent on nor entails any false belief, even though it is unknown whether it is possible to do. ${ }^{14}$

\footnotetext{
13. To see the significant role of explanation dimension of a normative reason in the debate see Setiya 2012.

${ }^{14}$. Furthermore, it might be supposed that there is an ignored unknown fact in such cases; however, as we will see in section 4, WTR excludes only close effective unknown facts, such that "ignorance [thereof] forms part of the explanation of what A actually does." There is no unknown fact in cases where no action can be done. Furthermore,
} 
3. Besides these major challenges, to which both classical reason internalism and reason externalism are subject, True Pointless Action poses a challenge specifically against affective reason internalism. ${ }^{15}$

Suppose that there are two double-seat tables in your office, and you are going to continue reading this paper sitting at a table. You go to sit on seat T1, which is four steps farther away than the other table T2. Even if we, human beings, have a strong bias to do less demanding works, it doesn't necessarily make it impossible or irrational to do more demanding work. You could have sat on the nearer seat without taking extra four steps, however, if you had wanted (or had a desire) to do that. If you are asked your reasons for this extra course of action, the most frequent responses would probably be on the lines of "pardon me?," "I have no idea," or more accurately, "there was no specific reason," "It just happened pointlessly." Similarly, if you are asked why you chose to sit on the right-hand-side seat of T1 instead of the left-hand-side seat, your answer would probably be the same: "no idea" or "without any specific reason." This implies that you did it pointlessly, without any normative or motivating reason (i.e., any operative considered beliefs) involved. These are indeed cases of True Pointless Actions. As mentioned above, there might be some unconscious cause operative in choosing the right-hand-side seat instead of the left-hand-side one, such as an underlying biological inclination or psychological bias; however, an unconscious cause is not to be considered as a practical reason, as far as I know.

True Pointless Actions are prevalent in our ordinary life as well as language; however, affective reason internalism accommodates none of them. According to Humean and Williamsian (in its 1979 biconditional formulation) internalism, you did have some normative reason for taking those extra four steps as well as choosing the right-side seat, simply because you wanted (had a desire) to do it. All actions desired and done are reasonable. There are no pointless actions-i.e., voluntary actions lacking any normative reason. Yet it seems counterintuitive that we, human beings, do all our actions whatsoever based on normative reasons.

We have already seen (in sections 1 and 2) that HTR and WTR can be represented, respectively, by a bijective and injective only (non-surjective) function from an agent's normative reasons to her actual affective attitudes; and we also mentioned that it might be thought that HTR and WTR can be captured by two bijective functions from an agent's normative reason to, respectively, her motivating reasons or normativized motivating reasons. However, as True Pointless Actions show, desiring doesn't imply the presence of an operative considered belief as a motivating reason for an action; desires can directly, per se, entail an action, and if so, according to the explicit formulations of HTR and Williams (in 1979), they would provide reasons for the actions without any kind of putative beliefs involved. So, these two recent bijective functions don't seem true of affective reason internalism (either in the Humean or Williamsian sense). According

Williams himself allows some paradoxical desires to function as reason-makers: however, if someone still thinks that Williams can insist on full consistency (which excludes even a desire which is so complicated that it entails some false belief only after in-depth exploration) in his account of having reasons, then such an objective sense of reason would undoubtedly face the explanatory challenge no less than the externalist account of normative reason.

15. I have inspired in this part partioaly by the Telic Desire Theoryin Parfit 2011:59. 
to HTR and Williams (in 1979), you have normative reasons even for pointless actions as long as you do indeed desire to do them. WTR, as formulated here based on his 1989 account, allows pointless actions by being silent about them. The classical externalists, in contra, are not as radical as classical reason internalists in believing that all human actions are subject to normative reasons.

These challenges make it hard to sustain either classical internalism or externalism. However, one can still maintain a weak Conative Reason Internalism which, interestingly, welcomes classical reason externalist theory as included under its heading. As we will see, one can still be commited to Reason Universalism, as the core idea of classical reason externalism, while paraphrasing one's thesis in terms of a weak counterfactual version of weak Conative Reason Internalism.

So, many recent contributors adopt a kind of Conative Reason Internalism as a reconciling theory which can meet these challenges, and so would be the most plausible theory of normative reason-good news, if it is indeed so. According to the schematic,

(3) Conative Reason Internalism: If an agent has a reason to $\phi$, then it follows by necessity that, at least on some occasions (under some particular conditions), she would be motivated to $\phi$.

Conative Reason Internalism, which is also referred to as "existing internalism," or "internalism about reasons,"16 is the cornerstone of Williams's classic argument; however, he dislikes the HTR and WTR, is not committed to HTM, and breaks with the exclusive role of desire-likes attitudes as the origins of motivations. Conative Reason Internalism is compatible with the idea of both cognitive and affective attitudes being motivation-makers.

\section{Conative Reason Internalism: From ideal suggestions to the commonsensical contextual thesis}

Conative Reason Internalism differs on the conditions under which there is a necessary relation between an agent's motivations and their reasons for action; however, all proponents of the thesis agree that under those conditions (whatever they may be), it is an individual agent who is capable of being motivated by a reason toward an action. Thus, it might be possible to subsume all the major suggestions under three idealized and one commonsensical category, as follows: agents could be (3.1) fully ideally rational (in its non-substantive trivial sense), (3.2) objectively ideally informed, (3.3) subjectively ideally moral, or (4) commonsensically contextually rational (in its substantive sense).

\footnotetext{
16. This theory, as a third-person view, is different form motivational internalism (i.e. moral judgment internalism) which refers to a first-person mental state, and says, necessarily, if an agent sincerely believes that $\phi$-ing is morally bad, then she is motivated not to do $\phi$.
} 
According to the first idealized condition,

(3.1) Fully Ideal Conative Internalism: If an agent has a reason to $\phi$, then it follows by necessity that, were she fully ideally rational, she would be motivated to $\phi$

(where an agent is fully ideally rational only if, if she has reasons, then she would be actually motivated to follow them)

This "condition" takes rationality to be equal to correctness, which is not only a mere stipulation (as opposed to a commonsense explication) of the term but is also clearly trivial, being a circular definition. It is circular to say that an agent has a reason to $\phi$ only if, if she has reasons that would actually motivate her to follow them, then she would be motivated to $\phi$. Such a circular definition just transmits the question of the nature of reasons posed in the analysandum to that in the analysis, without citing any substantive condition: so this is just a pseudo-condition. Such triviality can be identified in all idealized definitions, such as being ideally virtuous, if they are defined based on "reason." However, there are three substantive theses (two idealized and one commonsensical) proposed by contributors (including both classical internalists and externalists), which we still have to consider.

The second idealized condition, which this time is properly substantive, highlights the objective facts to guaranteeing an agent's being motivated whenever she is in fact subject to a normative reason.

(3.2) Objective information ideal conative internalism: if an agent has a reason to $\phi$, then it follows by necessity that, were she an objectively ideally informed agent, she would be motivated to $\phi$

(where an agent is objectively ideally informed only if she possesses "all information," "has a vivid awareness of all relevant contingencies," and "has no false belief." $)^{17}$

Now consider Case 2, in which Philip has just one dollar in his pocket, and he wants to give it to one person, i.e., his poorest neighbor. He knows that Sarah is his poorest neighbor, and he intends to help Sarah (at $\left.\mathrm{T}_{1}\right)$. It seems intuitive that Philip has reason to do that, due to the facts that he wants to do a moral action (i.e., help his poorest neighbor), and that Sarah is his poorest neighbor. However, Ross, another neighbor who was not poor at $T_{1}$, suddenly goes bankrupt and nobody (including Philip and even Ross himself) has heard about this yet, so nobody knows that Ross at

17. See, Smith 1994; Joyce 2001; Darwall 1983. 
$\mathrm{T}_{2}$ is the poorest person around. It seems intuitive that Philip (at $\mathrm{T}_{2}$ ) still has a reason to help Sarah, in the absence of any defeater for his knowledge about Sarah's being the poorest neighbor; given that he wants to help the poorest neighbor, it would be ridiculous if he stopped helping Sarah and decided to give the dollar to Ross, who at $\mathrm{T}_{1}$ is known as a rich company owner. However, if Philip knew all relevant objective information he would definitely decide (and would be motivated) to help Ross instead of Sarah, due to the fact that he wanted to help his poorest neighbor (which logically refers to one person) and Ross is the poorest neighbor. So, the objectively informed ideal condition is strong.

In another case (Case 3), Phillip wants to help a poor person, and his neighbor Sarah has a very old-fashioned car and usually wears used clothes; so he comes to believe that Sarah is poor, and he decides to help Sarah. But Sarah is a company owner and is not a poor person at all. But she goes bankrupt, and so becomes a poor person. Given that Philip wants to help Sarah as a poor person, and she is, now, poor in fact, it seems that Philip has still reason to help Sarah as a poor person-having a reason allows reasons to be true by luck (as happened in Case 1). Then Philip, based on his practical reasoning, reasonably helps Sarah. However, if Philip knew all relevant objective information, including the fact let us say that Sarah is the owner of a legal sex company (where this is contextually unknown), then given his moral considerations about the legal sex industry he would probably hesitate to help her, and would not be necessarily motivated to help her. If this is correct, it shows that being motivated under the objectively informed ideal condition is contingent.

\section{One Objection against Case 3}

It might be said that Philip's desire to help a poor person (and his relevant belief about its correctness) was actually not unconditional from the very beginning, but constrained to apply to a poor person who is not an owner of a legal sex company. If so, from the very beginning he never wanted (had no desire to) help a person like Sarah; had he known that Sarah is a legal sex company owner, he never would have been motivated to help her; and so he has no reason actually to do that because there is an ignored fact (i.e., that Sarah is a legal sex company owner) in the caseor his reasoning involved a false belief (i.e., that Sarah is not a legal sex company owner). How should we respond to this?

First, it seems the objector invokes Williams's purported intuition on the no effective false belief condition to challenge a pre-philosophical intuition which says that having reason is not sensitive to all relevant objective facts, and so Philip was reasonable in helping Sarah in the absence of any contextually inaccessible defeater. However, it seems that the pre-philosophical and more universal intuition, which it seems obtained in Case 3, is more reliable than Williams's own technical intuition. Williams's intuition demands we take some contextually inaccessible information (i.e., knowledge of the absence of all effective false beliefs) into our practical reasoning process if want to act reasonably, and so oddly he considers Philip as an irrational person just because he missed what contextually was impossible for him to take into his practical reasoning. 
That being said, secondly, I believe that even the strong Williamsian intuition cannot rule out this case, due to the fact that there is no effective false belief here. "Sarah is not a legal sex company owner" is false but is not believed; Philip has no idea about Sarah's job, and so he doesn't believe either that she is the owner of such a company or not. Moreover, there is no Williamsian neglected reason relative to the unknown fact "Sarah is a legal sex company owner." Williams explicitly states that an unknown fact is a reason-maker only if it is "fairly close and immediate" to the relevant action, such that its being ignored "forms part of the explanation of what A [agent] actually does." Given that an ignorance can figure in an explanation of an action only if it produces a false belief, for Willimas the effective unknown fact (which had it been known would change an agent's affective attitudes) is a reason-maker only if it produces a false belief which partly explains the action - that is, a close effective unknown fact is a reason-maker. But Philip, in Case 3, has no false belief: that is, the effective unknown fact about Sarah's job has not produced any false belief, and doesn't play an explanatory role there; so the unknown fact doesn't engender any neglected reason, in a Williamsian sense. Philip wanted to help Sarah, as a poor person, and there is no effective false belief or close and immediate effective known fact.

Moreover, the objector has imposed some extra meaning (i.e., the condition of being "not an owner of a sex company") onto the opening line of the story (i.e., "Philip wants to help a poor person"). The first proposition of the case clearly refers to the agent's unconditional desire to help a poor person. According to Williams, two kinds of desires are reason-makers. First, the present one, and secondly, the unknown desires, but only if $\varphi$-ing is "rationally related" to them. A rational connection for Williams can be informal, however, it plays a partial role in the explanation of doing the action (Williams 1995). So, they cannot be fully unknown, like underlying unconscious explanatory reasons (say, causes) or fully unknown purported desires, which have no explanatory roles.

Williamsian unknown desires are conscious desires upon question: if the agent is asked about them, they immediately answer and clarify them. The purported desire "not to help a sex company owner" is clearly not present one, and it is also not a kind of upon question desire, which would be mentioned immediately in response to a relevant question. Philip, if asked about "not helping a legal owner of a sex company," would become doubtful about it, not express a positive desire not to extend such help. So it is not an upon question conscious desire: at most it is just an upon question doubt, which cannot play the role of a desire in the Williamsian intuition. So the only remaining Williamsian desires here are two present ones: the precedent unconditional desire of "desiring to help a poor person," and later conditional one of specifically "desiring to help Sarah." And, as observed above, the latter is not based on any effective false belief or close effective unknown fact; the objector's invoking the Williamsian intuition is explained away. So, even the Williamsian intuition recognizes Philip as a reasonable agent in his action to help Sarah. However, had he known the far unknown fact about her job, he would become doubtful and would not necessarily be motivated to help her-so objective conativism is false.

Notice that Williams's affective intuition can accommodate Case 3, but this doesn't mean that it would be more plausible than Objective Information Ideal Conative Internalism. As 
observed in section 3, the major challenges it faces have left affective internalism seeming both uninteresting and hard to believe. Furthermore, the affective theories (neither HTR nor WTR) cannot accommodate the rest of the cases (Cases 4, 5, and 6) in this paper.

Having reason not only allows true-by-luck reasons (as we saw in Case 1) but is also still not sensitive to all effective relevant facts; objectively, idealization is not fit to cover all extensions of normative reasons. Maybe a subjectively ideal moral condition works, then.

3.3 Subjective Morally Ideal Conative Internalism: If an agent has a reason to $\phi$, then it follows by necessity that, were she a subjectively moral ideal agent, she would be motivated to $\phi$

(where an agent is subjectively morally ideal, only if she is ideally virtuous. ${ }^{18}$

Consider Case 4, in which Philip, as an ideally moral agent, wants to help a poor person and believes (without caring for any further information that might be around) that Sarah is the right person for his purpose. So he decides to help her. And Sarah is indeed poor; however, she is also a well-known human trafficker, who has invested all her money in her job, and so nobody in the context wants to help her, all considering helping her to be immoral and irrational. Is Philip an exception? It seems that every agent, including the ideally moral person, has a strong reason to care about the accessible relevant information in the context to prevent themselves ending up doing immoral and irrational actions. Being sensitive about the morally negative consequences of our actions is a basic constituent of being a rational agent, as well as having a normative reason for an action. Philip has a reason not to help Sarah, a well-known human trafficker, even though as a subjectively ideally moral agent he is motivated to help her in this case. Being ideally moral is not sufficient to be motivated towards a reasonable action (here, not helping Sarah).

It might be said that Philip has reason to help Sarah because having reason is not factive. And it is indeed true that having a reason is not factive: an agent might have a reason $\mathrm{R}$ to do some action, even though $\mathrm{R}$ is not true- in fact, $\mathrm{R}$ is not a reason for that action to be done. So, this allows Case 2, in which Philip had reason to help Sarah as his poorest neighbor, yet there was no reason for Sarah to be helped as the poorest neighbor because Ross was the real poorest neighbor. Similarly, in Case 3, Philip has reason to help Sarah as a poor person, however, this doesn't necessarily mean that helping a poor owner of a legal sex company is correct. Furthermore, even a factually true reason (i.e., one which in fact is a reason for an action to be done) can be based on false belief (as in the true by luck belief in Case 1). However, not being factive doesn't imply that having reason could be fully falsive. A counterfactual condition which allows all internal considerations to be normative reasons, no matter whether they are all false or not, is as trivial as fully ideal conativism (3.1) - a pseudo-counterfactual condition which allows being itself rejected even if it was correct. ${ }^{19}$

18 . See, McDowell 1995; Brandt 1979.

${ }^{19}$. For instance, see, Schroeder 2007. 
The non-trivial idealized conditions (either objective or subjective) for conative internalism are not convincing, so maybe a substantive commonsensical idea, accompanied by an appropriate balancing contextual condition which in some degrees satisfies both the objective and subjective dimensions, works well. This substantive thesis is neither so objective such that excludes Case 2 and 3, nor so subjective so that it includes Case 4. Such a contextually full rational condition can be defined best by a bijective function from an agent's normative reasons to her motivations provided that she is a contextually rational agent.

(4) Contextual Conative Internalism: If an agent has a reason to $\phi$, then it follows by necessity that were she contextually rational, she would be motivated to $\phi$

(where an agent is contextually rational only if she is both psychologically normal relative to the (moral, logical, empirical, etc.) standards in the context, and also considers the contextually accessible information. ${ }^{20}$

Such a definition includes substantive minimal rationality or practical rationality, which is a considered as a condition of agency (Korsgaard 1986 \&1996); however, it is not limited to that. An agent may be not contextually rational.

\section{Contextual Conative Internalism: From agentic contexualsitm to austere contexualism}

All the abovementioned counterfactual suggestions, either (objectively or subjectively) idealized or contextualized, were exploring a connection between a certain individual agent and her conative attitudes in some situations, whether trivial or substantive. We can call this common feature Agenticism, and call the substantive contextual conativism which appeals to it, and which is seemingly the best candidate so far, Agentic Contextual Conative Internalism.

Consider Case 5, in which Philip, as a fully contextually rational agent (who is contextually normal relative to the standards, and aware of the contextually accessible information) has just one dollar to donate, and believes that it doesn't make sense to exchange for smaller denominations to donate to several poor persons, so he wants to give it to only one poor person. He goes into downtown San Francisco to find a poor person to donate the one dollar to. He sees two poor people sitting on the two corners of the stairs next to the train station: Sarah, a poor white woman with a yellow shirt on the seat to the left hand side of her, and Ross, a poor black man with a red jacket on the seat to the right hand side of him. Philip has reason to give the money to each of them, either Sarah or Ross. However, he decides to give it to Ross. Given that he has just one dollar and he wants to give it to one poor person, he is naturally not motivated to help Sarah (and cannot be), even though he has still reason to do so; and if suddenly (say pointlessly) his mind changed and he gave the dollar to Sarah, nobody would say he was not justified in doing that. He was simply justified to help either one of them, just because he wanted to help a poor person and that could be

${ }^{20}$. For a roughly similar contextual definition, see Henning 2014. 
satisfied by each of Sarah and Ross. So, Philip, the contextually rational agent, has reason to help Sarah, but is not motivated to do so. If such an example is intuitively correct, as it seems to be, it shows that a certain individual agent's motivation is only a contingent condition for having reason, even though he is contextually rational-so Agentic Contextual Conative Internalism is still strong.

\section{Two Objections against Case 5}

First, it might be said the counterexample works only if Philip's decision to help Ross was entirely random; however, for the impossibility of a real randomness, there should be another reason (maybe a cheap one) at work for giving one dollar to Ross instead of Sarah. If so, the extra reason would swing him towards one choice (helping Ross) against the other (helping Sarah), and so Philip, in this sense, has no reason to help Sarah. (Notice that because Philip is a contextual rational agent who lives in the Bay Area, he definitely would not choose his case based on sex or race.)

I would say in response that even given the impossibility of randomness, this does not necessarily show some new reason at work. Imagine that Philip decided to give the dollar to Ross just because of some unconscious biological inclinations or psychological bias. Suppose Philip gave the dollar to Ross just because he would be taking the dollar out from his right-hand pocket and for a right-handed person giving it to someone on his right is unconsciously more practical than giving it to someone on his left; or suppose that Philip, unconsciously, is red-black color biased, or even that there is an unknown (even for bystanders like us) unconscious cause involved. As we observed in section 1, unconscious causes (either known by a third-party bystander or wholly unknown) can by no means be considered as normative reasons for an action, even in the radical Humean sense. Notice that being right handed or red-color biased by no means prevents an agent from being rational.

Secondly, it might be said that Philip has the motivation to help one poor person, and given that Sarah is poor, and would exemplify the abstract singular term "poor-ness," Philip is motivated to some degree to help Sarah as well. Perhaps the motivation is not a strong one, though, and for the sake of some hinderences (like financial limitations), it is just a weak motivational sense which is in every desire as a mental state. So, a weak sense of motivation to help Sarah is indeed involved, and so Agentic Contextual Conative Internalism is not false.

It seems that the objection points towards a contextual affective internalism, which is weaker still than Contextual Conative Internalism. ${ }^{21}$ So, to make the objection still stronger let's paraphrase the first line in terms of the weaker attitude of contextual "desire". Given that Philip wants to help one poor person, it follows by necessity that he would desire to help Sarah as well as Ross, but due to some financial limitations plus some unconscious biological or psychological causes, he is not strongly or actually motivated to help Sarah.

\footnotetext{
21. It is similar to Counterfactual State model which is proposed in response to the Conditional Fallacy. For similar arguments, see Hubin 1996; Johnson 1999, § III; and Sobel 2001; an ancestor is Shope 1978.
} 
The response is that "desire" (as well as motivation), in spite of "having reason", is not closed under the exemplification of Disjunctive Universal terms (like one poor person), unlike Conjunctive Universal terms (like every poor person). Consider the following sentences:

(i) Philip wants (has a desire) to help one poor person.

(ii) Philip wants to help every poor person.

The semantical content of "one poor" in (i) can be given by multiple exclusive ors, which means that he is going to help only one person, no matter whether she is $\mathrm{X}, \mathrm{Y}$ or Z, etc. So, when he has determined a certain poor person (say X), the exclusive or implies that he has no desire to help any other person: "one poor" is a Disjunctive Universal term. However, the quantified universal term "every poor" in (ii) is cashed out by an unlimited conjunctive chain of all objects which exemplify the poor-ness. Such conjunctive universality is inferred from the explicit universal quantifier in "every person"- - let us call it a Conjunctive Universal term.

Suppose that Sarah is poor. Given (ii), Philip should (has a strong reason) to help Sarah, who exemplifies the abstract singular term poor-ness; otherwise, if he doesn't do that, he can be correctly accused of self-contradiction, or a violation of (ii). So, the desiring or being motivated to a conjunctive universal term, necessarily entails the desiring or being motivated to every example which exemplifies the relevant abstract singular term. So, desire (as well as motivation) is closed under the exemplification of Conjunctive Universal terms. Now replace "want" in (ii) by "has reason":

(ii)' Philip has reason to help every poor person

Given that Sarah is poor, it seems that "having reason" is similarly closed under the exemplification of "every poor," and Philip is justified to help Sarah. Therefore, both "desire" (as well as "motivation") and "having reason" are closed under the exemplification of both Absolute and Quantified Conjunctive Universal terms. What about the disjunctive term "one poor"?

Suppose that Sarah is poor, given (i) it seems that it is not contradictory if Philip says that he wants to help Ross instead of Sarah. It doesn't violate (i), and the exclusive disjunctive sense of "one poor" implies that Philip has no desire (nor any kind of motivation), and indeed cannot desire (or be motivated) to help any other person, including Sarah. Desiring (and being motivated to adopt) a Disjunctive Universal term like "one poor" doesn't necessarily entail desiring (and being motivating to adopt) every example of it. So desire, as well as motivation, are not closed under the exemplification of "one poor." Now, let us put "has reason" instead of "want" in (i):

(i) Philip has reason to help one poor person.

Like (ii)', there is no doubt that Philip is justified if he donates one dollar to Sarah, just as he would be justified if he gave it to any other poor person, like Ross. Therefore, "having reason" is closed 
under the exemplification of the Disjunction Universal term of "one poor," while "desire" (as well as motivated) is not. So, in Case 5, Philip has reason to help Sarah (as well as Ross), while he has neither desire nor motivation to help Sarah.

To shed still more light on this, suppose that you are going to marry an attractive, welleducated, and devoted person, and these are all your criteria to choose your best match. Given that $\mathrm{R}$ and $\mathrm{M}$ are both qualified relative to your standards, you are fully justified (have reason) to marry each one of them; suppose that after dating them, you decided to marry R, either due to the fact that you are unconsciously inclined towards left-handed people, like R (although you are not able to mention any reason specifically when you are asked why you were motivated, and then decided to marry R), or due to an underlying physiological inclination which is not known even by a thirdparty bystander. If so, after deciding to marry R, you naturally don't desire (or are motivated to) marry any other person, relative to the fact that you are monogamous. Yet you are still justified to marry each of those two qualified persons, and if your mind, unconsciously, changed, and you decided to marry Matthew, nobody would blame you for doing an unreasonable action.

Accordingly, it seems that Agentic Contextual Conative Internalism cannot cover a number of revalent cases in which a contextual rational agent (like Philip) has reason to do some action (like helping Sarah), however, for the sake of some unconscious opposing biological inclinations or physiological biases (which, once again, are by no means considered extra normative reasons at work), she neither has a desire nor is motivated, even in a weak sense, to do that action. Agenticism is strong, however, and it seems that a contextual account which is not only contextual about the information or standards, but also contextual relative to the agents, and not restrained to a certain one, might work here.

(5) Austere Contextual Conative Internalism: If an agent has a reason to $\phi$, then it follows by necessity that, were she contextually rational, or if there were another contextually rational agent in the context, she would be motivated to $\phi$

(where an agent is contextually rational only if she is both psychologically normal relative to the (moral, logical, empirical, etc.) standards in the context, and also considers the contextually accessible information. $)^{22}$

Accordingly, the conative internalism's necessity pairs with the context in which the relevant kind of motivation to $\phi$ obtains (no matter who the subject is), instead of a certain individual agent in that context. An agent has a reason only if there is a motivation for $\phi$-ing in the context.

Philip has a reason to help Sarah - yet is unmotivated to do so - because there is another contextual rational agent in the context who is motivated to help Sarah: maybe because she is a left-hand person or, unlike Philip, is unconsciously yellow-white color biased, or for any unknown underlying cause whatsoever. Similarly, you are still justified to marry Matthew, even though you

\footnotetext{
22. For a roughly similar approach in moral judgment internalism debate, see Tresan 2009.
} 
are not motivated to do that after your decision to marry $\mathrm{R}$, due to the fact that in the context there is a motivation to marry a qualified person like Matthew; for example, if another agent, with the same criterion for marriage (i.e., being attractive, well educated, and devoted) is there who is, unconsciously, right-hand biased, they would be motivated to marry Matthew.

Maybe such an austere thesis can somehow enable us to maintain our belief in a weak Contextual Conative Internalism, in the sense that there is a necessary counterfactual connection between a certain (not necessarily rational) agent's normative reason and the motivation belonging to another contextual rational agent in the context.

\section{From Austere Contextual Conative Internalism to Agentic Cognitive Reason Contextualism}

All five accounts suggested so far are either some kind of conativism or are based on it (like the first two affective theses), and it seems that Austere Contextual Conative Internalism stands out as best-placed to accommodate the counterexamples, and probably to overcome most challenges described in section 3 .

However, even such an austere conative version is not sufficient to meet our strong intuition in the following story (Case 6), which refers to a possible context in which all agents are right-hand dominants as well as red-black color biased, exactly like Philip. Here, given that the other conditions in Case 5 obtain, Philip has a reason to help Sarah, even though he is not motivated to do so. Similarly, in this possible context, suppose that all the other contextual rational agents would similarly decide and be pointlessly motivated to help Ross instead of Sarah, if they were faced with Philip's dilemma; perhaps because of some unconscious biases, such as taking the dollar from their right-hand pocket and giving it to the Ross being more practical for those righthanded persons or because they are all red-black color biased. Does it follow that those rational agents who wanted to help one poor person, have no reason to help the left-hand-side poor old woman with a yellow shirt, who is Sarah? It seems intuitive that Philip, and all the other contextually rational agents, are justified if they helped Sarah, and it seems that having reason to help a poor person is not so ridiculous to be tied to the geographical position of the poor person or a shirt color. As I explained above, having reason is closed under the exemplification of the Disjunctive Universal term, such as "one poor" person, and this implies that all other rational agents in the context have reason to do that, no matter why they unconsciously or pointlessly decided to help Ross instead of Sarah. Exactly because of this, if (again pointlessly) one of those agents changes his mind and gives the one dollar to Sarah, he would be fully rational and justified, relative to his good intention of making a donation to one poor person. Notice, again, that being left- or right-handed as well as being yellow or red-black color biased neither increases nor decreases an agent's rationality. Moreover, I believe that any suggestion to take a physiological feature (like being left-hand person) into account of the semantics of reason and rationliaty is not just odd alarming!

It might still be possible to reformulate Austere Contextual Conative Internalism in terms of some close or far (if needed) possible worlds relative to our possible context, so as to keep a very weak and uninterestingly odd necessary connection between a given (not necessarily rational) 
agent's normative reason in the actual world and the motivation belonging to a possible contextual rational agent in the close or far possible world relative to our possible context. Besides the fact that such suggestions would probably face other similar counterexamples in terms of a possible context, in all these close or far possible worlds in which all the contextual rational agents would pointlessly ignore one reasonable action, it seems that such possible suggestions are as trivial as the fully ideal conative internalism, and are just pseudo-conditions. Who denies that it is not contradictory that a rational contextual agent should become motivated to do a reasonable action? What is right with such odd insisting to find some uninteresting conative internalism? Is int it pointless insistence? I will come back to it soon.

The other suggestion which comes to mind is derived from reflection on the capacity of being motivated towards an action, which is employed by some contributors. ${ }^{23}$ The basic condition of the capacity of Being-motivated-by-reasons as an actualized potentiality which is still potential to more actualization, was largely thought to be a good ground to provide a substantive condition for "having reason"; however, it seems that such a capacity itself is, semantically, underpinned by a still more basic condition of the capacity of Reasons-understanding. An agent has the capacity of Being-motivated-by-reasons only if she has the capacity of Reasons-understanding, but not vice-versa. Imagine a hard amoralist who sincerely asserts that "I believe that $\phi$-ing is morally wrong, but I can never be motivated to do that" without contradicting himself. ${ }^{24}$ Such a hard amoralist still has the capacity of understanding- $\phi$, but he has de-actualized, to some extent, even the primary actuality which is called the capacity of Being-motivated-by-reasons (here, moral reasons).

Let us postulate such a Hitler-like man, who sincerely asserts that he cannot be motivated to stop killing people just because it is immoral, and as a matter of fact never in his life succeeded in curbing his murdrous urges; it seems that such a hard case would be better explained by considering him as a man who has de-actualized, to some extent, his capacity of Being-motivatedby-reasons, rather than considering him as a man who has the capacity of being motivated by this moral reason even though he has never used it in his life. The latter explanation would be still more implausible if we think of Adolf Hitler himself, say, as a person who does the same as he did in this actual world in almost all the close possible words he could be in. Notice that the "capacity" should not be taken as equal to logical possibility, thus making the former explanation look less plausible.

It seems that human beings have the capacity to both actualize (more) or de-actualize their capacity of Being-motivated-by-reasons; in the former case, it leads to this being the actual motivation on some occasions, while the latter case entails the incapability of Being-motivated-byreasons, at least to some extent. So it seems that the capacity of Being-motivated-by-reasons is contingently true of the "agent" who by nature and necessarily has the capacity of Reasons-

\footnotetext{
23 . See, Setiya 2012.

24 . Notice that the capacity should not be taken as a pure potentiality so that make such case looks implausible.
} 
understanding. If so, does it mean that a such hard amoralist has no reason to stop killing innocent people?

It seems that a hard amoralist, the Hitler-like figure described above, has to some extent de-actualized his capacity of Being-motivated-by-reasons, yet he still has reason to stop killing people and is actually responsible for his wrong actions. Why? As we see below, this is just because he still can make evaluative sense of the relevant moral idea and can understand why killing people is considered wrong. Of course, if there are some super hard amoralists or arationalist who cannot even make sense of basic moral or logical reasons, they would be just pseudo-agents: a man who fully de-actualized his capacity of Reasons-understanding, if it is possible to reach this point voluntarily, would be judged as a crazy person, and no longer subject to normative reason. However, unlike ordinary 'crazy' people, he is still responsible for the negative consequences of his actions, due to the fact that he ended up in such a disastrous epistemic situation voluntarily, not through accident of deterministic nature.

It seems that the vulnerability of different versions of conative internalism faced with the six abovementioned counterexamples, comes from the fact that many practical reason theorists have struggled to import an affective or conative attitude into the nature of "having reason," instead of concentrating on more basic cognitive attitudes like the capacity of Reasons-understanding. Yet it seems that by appealing to a cognitive attitude which is fully independent of agent-affective and conative attitudes, we can make better sense of our commonsensical sense of "having reason." 25 Such a non-internalist thesis might issue in what follows:

(5) (Agentic) Cognitive Reason Contextualism(CRC): If an agent has a reason to $\phi$, then it follows by necessity that, were she contextually rational, she would make an evaluative sense out of the propositional content of $\phi$-ing or would understand why $\phi$-ing is considered as the right action in the relevant context.

(where an agent is contextually rational only if she is both psychologically normal relative to the (moral, logical, empirical, etc.) standards in the contexts, and also considers the contextually accessible information)

Intuitively nobody would admit that a contextually rational agent can have a reason to $\phi$ although they cannot make any sense out of the propositional context of $\phi$-ing, or is not capable of understanding its rightness. It seems contradictory to assert that an agent has a reason which is not even understandable for her. (The plausible similar form of expression is to say that there are some reasons which are not understandable for an agent.) If so, it seems that the cognitive attitudes of making sense of or understanding something's rightness is the real substantive constituent of a

\footnotetext{
25. "Understanding" is sometimes thought of as a factive mental state (Kvanvig 2003), and on this basis it might be questioned how it is possible to take a factive mental state as the basis for a non-factive state like having reason. if so, it means that the objection pre se is understandable, but it doesn't mean that it is necessarily true. Therefore, I, among others (like Elgin 2009 \& Riggs 2009), adopt the view that understanding is not factive.
} 
normative reason. Notice that "evaluative" in the definition also indicates making sense of a practical reason, not just a theoretical one. A contextually rational agent can definitely make sense of many theoretical reasons as well.

Cognitive Reason Contextualism is fully independent of an agent's desires and motivations even in the weakest counterfactual sense of austere contextualism, and so it is neither affective nor conative internalism. It does not need to be austerely contextual so that it can overcome the challenges and accommodate the counterexamples. Being simply agentic also increases the simplicity of the account, along with its explanatory power. However, because the agentic sense is the default meaning of an agent being contextual, and for the sake of abbreviation, I refer to it without the "agentic" adjective.

Cognitive Reason Contextualism (henceforth CRC) can accommodate all the aforementioned counterexamples, as follows. In Cases 6 and 5, Philip, like the other contextual rational agents around, has a reason to help Sarah (the poor old woman with the yellow shirt) as well, just because it makes sense for him to help Sarah or Ross regardless of unconscious physiological inclinations or psychological biases which might block the motivational attitudes. In Case 4, Philip has reason not to help Sarah (the well-known human trafficker) because it was understood as a wrong action to do that if he was contextually rational, who cares to the contextually accessible information as well, instead of merely being a subjectively moral ideal agent. In Cases 3 and 2, Philip has a reason to help Sarah due to the fact that it makes good sense to him, as a contextual rational agent who is sensitive just to the contextual information, to help respectively "a poor person" or his "poorest neighbor," regardless of the objective facts which are unknown in the context. Finally, in Case 1, Philip still has a reason to help Sarah, just because it makes sense to a contextual rational agent to help a "poor person," being by definition not sensitive to true by luck cases.

CRC will satisfy the challenges as well. According to CRC, we cannot make any evaluative sense of our taking three extra steps to sit on the chair while there is a nearer one available; we don't understand why it can be considered as right action. We simply think of it as an action done pointlessly. So, this allows actions without reasons-true pointless actions is satisfied.

Moreover, in spite of the other alternatives, CRC would also meet the Explanatory Challenge without sacrificing one of the two major dimensions for normative reasons, i.e., the justificatory (or normativity) and explanatory dimensions, to satisfying the other. It offers a kind of balance between subjectivism and objectivism on the required possibility in the debate. According to CRC, the normative ought implies a contextual can. The intuitive sense of the can or explanatory dimension of having a reason is contextual possibility, which is not psychological in its affective or conative scenes, nor is it the anti-psychological physical one. The contextual possibility includes both the cognitive possibility of understanding a reason and the physical possibility of accomplishing the relevant action, regarding the context. A contextually rational agent has a reason to $\phi$ only if she can make evaluative sense out of it; and then, relative to the context, she is able to desire, or be motivated to or actually $\phi$, however, all the following affective, conative, or actual consequents obtain just contingently. An understood external consideration can 
be actually followed, on some occasions, by the agent who could make an evaluative sense out of it, and if so it plays some explanatory role in a causal chain which fully explains the reasonable action done. If an agent can make sense of a consideration, he definitely (at least on some

occasions) can follow it, and do the relevant action. So, the basic cognitive sense of the possibility in the principle, satisfy the explanatory dimension of normative reason very well.

The last challenge facing CRC is reason universalism (including the moral Central Problem in the debate), which is a problem for both classical camps. According to reason Contextualism the little girl in a tribe who is "not been properly brought up" has no reason to follow liberal democracy because she cannot make any sense of liberal democracy, whereas the hard amoralist had strong reason to not kill innocent people due to the fact that he could make sense of why it is largely considered as a wrong action (McDowell 1995). CRC constrains an agent's reasons to her contextual cognitive ability, and in this way it can accommodate all similar moral and rational counterexamples in both camps.

The reason universalism thesis, as the core sense of classical reason externalism, is fully independent of an agent's psychological attitudes (including her contextual limited cognitive ones) and so cannot accommodate certain counter examples (like the little girl in the tribe). However, the thesis is derived from two strong intuitive ideas of Reason Absolutism (the universalized form of moral absolutism), and Reason Rationalism (the universalized form of moral rationalism). Is there any plausible sense of CRC which both keeps its explanatory power in accommodating the counterexamples and explains away the strong intuition behind Reason Universalism, maybe in one specific sense? I believe so.

\section{De dicto Cognitive Reason Contextualism}

Consider the following true sentence: Philip believes that his neighbor is poor. Given that he believes that there is a necessary relation between the object and predicate of the sentence, the sentence can be understood in two ways: first, Phili, knows Sarah to be a poor person, but is not aware that she has recently moved into his neighborhood. According to this de re sense of the sentence, Philip's belief is about an actual property of Sarah (while he does not know the truth that she is his neighbor).

De re proposition: Philip believes that his neighbor is necessarily poor

Secondly, Philip, based on some evidence (like her/his broken car and old house) believes that his neighbor is poor, although he has never met her/him. According to this de dicto sense, even though Philip's belief is true, it does not say anything about an actual property of Sarah (his unknown neighbor). According to the

De dicto proposition: Philip believes that necessarily his neighbor is poor 
Similarly, CRC in effect might say something about a metaphysical property of reason. If so, CRC, which says "if an agent .... it follows by necessity ...." is a de re thesis. This implies that there is a metaphysical connection between normative reasons and the contextually rational agent's cognitive attitudes. That is, in every possible world, including that in which commonsensical linguistic intuitions are very different, there is a metaphysical tie between explanandum and explanans. Such a strong metaphysical thesis is neither intended here nor required to overcome the challenges or accommodate the counterexamples. It is not compatible with any reading of reason universalism either. Moreover, it seems that for every cognitive contextual reason, there is a world, in which it takes such an observed necessary connection-viz. a possible world at which the commonsensical linguistic intuitions obtain differently.

However, if think of CRC a priori, that is as indicating simply a conceptual truth between "having reasons" and a contextual rational agent's cognitive attitude, then it would be a de dicto thesis. This leaves us with the following:

(6) De dicto Cognitive Reason Contextualism: Necessarily, if an agent has a reason to $\phi$, then it follows that, were she contextually rational, she would make an evaluative sense out of the propositional content of $\phi$-ing or would understand why $\phi$-ing is considered as a right action in the relevant context

(where an agent is contextually rational iff she is both psychologically normal relative to the (moral, logical, empirical, etc.) standards in the contexts, and also considers the contextually accessible information)

De dicto Cognitive Reason Contextualism (DCRC), among other advantages, is also compatible with the intuition behind reason universalism, in one sense, no matter how it would be explained. ${ }^{26}$ It is compatible with de re Reason Universalism, a metaphysical idea about external unconditional objective normative reasons, which usually is referred by this sentential form: There is a reason for $\mathrm{C}$ (a certain action) to be done. ${ }^{27}$

\section{Conclusion}

DCRC offers a bijective function from an agent's normative reason to her cognitive evaluative thought provided that she is a contextual rational agent (Figure 3), and it functions as a reconciliation thesis which is farther from the internalists than the externalists. Though it is fair due to the fact that even the weak versions of de dicto conative internalism (like the austere definition 4) would be faced with some intuitive counterexamples (like 6) which could be

\footnotetext{
${ }^{26}$. I am inspired by Tresan 2006 in this section.

27. It is still more objective than the form of "There is a reason for an agent to do C", which largely is thought as the bearer of external reasons. For a discussion on the normative forms of reason statement, see Finlay 2014.
} 
accommodated even within the strong de re externalism. Anyway, DCRC is neither internalist nor externalist as such, it is simply the only remaining alternative in the debate.

According to DCRC, it seems that some basic oughts are conceptual truths of agency; that is, in spite of the Humean belief about the impossibility of deriving ought from is, they are correctly derivable from the plain proposition that "there is an agent." Some might believe that these unconditional conceptually true oughts are limited to a priori logical oughts such that being motivated by them is constituent of being an agent-such that someone who lacks such motivations (in response to those basics oughts) is not considered as an agent. However, it seems that these basic oughts neither necessarily motivative nor are limited to some basic logical oughts. If it is plausible that human beings (say the agents) have the capacity to de-actualize their capacity of Being-motivated-by-reasons, then it seems that there are some basic moral reasons shared by all agents, even the hard amoralists, in terms of their primary capacities of Reasons-understanding, that play the central role in the constitution of agency. However, determining the existence of such basic reasons, such that being able to understand them is the primary constitutive of being an agent, are properly questions for experimental psychology.

We have travelled along a technical analytical and maybe indeed boring path, hoping to reach the most commonsensical intuitive explanation for our everyday practical reason. If I have reached such an account with DCRC, it is worth it. I believe one of the most significant pros of DCRC, albeit also shared by some of his rivals, is that it allows its followers to recognize all the other practical theorists, even the most skeptical ones, as fully rational in their actions relative to their contexts. Nobody deserves to be considered as irrational just because they understand things differently, particularly if they are also great minds.

Figure 3: DCRC's bijective function

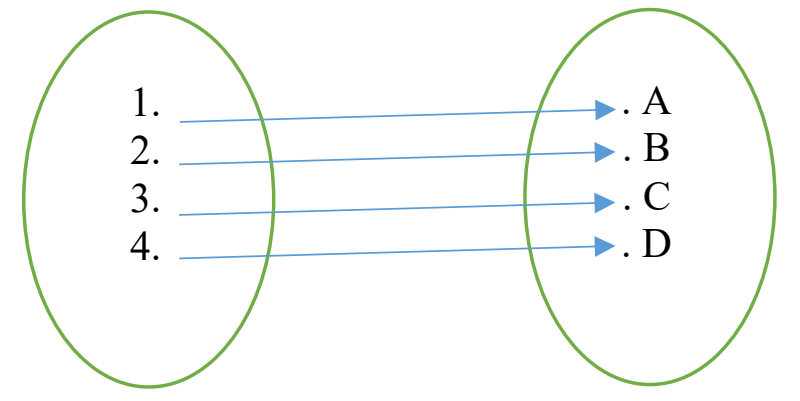

An agent's normative reasons $\rightarrow$ her cognitive evaluative thoughts provided that she is a contextual rational agen 


\section{References:}

Afroogh, Saleh (2019). Contextual Reason and Rationality. Master's thesis, Texas A\&M University. Available electronically from http : / / hdl .handle .net /1969 .1/186349.

Brandt, R., (1979). A Theory of the Good and the Right, New York: Clarendon Press.

Darwall, S., (1983). Impartial Reason, Ithaca: Cornell University Press.

Elgin, Catherine Z., (2009). “Is Understanding Factive?”, in Haddock, Millar \& Pritchard 2009: 322-330 (Appendix C).

Finlay, S. (2014). Confusion of Tongues: A Theory of Normative Language. New York, NY: Oxford University Press.

- Finlay, S., (20090, The Obscurity of Internal Reasons, Philosophers' Imprint, 9 (7): 1-22.

- Finlay, Stephen and Schroeder, Mark, "Reasons for Action: Internal vs. External", The Stanford Encyclopedia of Philosophy(Fall 2017 Edition), Edward N. Zalta(ed.), URL = $<$ https://plato.stanford.edu/archives/fall2017/entries/reasons-internal-external/>.

- Henning, Tim. (2014). "Normative Reasons Contextualism." Philosophy and Phenomenological Research 88: 593-624.

- Hirstein, W. (2009), 'Confabulation' in (eds.) Bayne, T. Cleeremans, A., \& Wilken, P., Oxford Companion to Consciousness, Oxford: Oxford University Press.

- Hume, D., (1739/40). “A Treatise of human Nature,” edited by David Fate Norton and Mary J. Norton, Oxford/New York: Oxford University Press, 2000.

- Korsgaard, C., (1996). The Sources of Normativity, Cambridge: Cambridge University Press.

- Korsgaard, C., (1986). Skepticism about Practical Reason, Journal of Philosophy, 83: 5-25.

- Kvanvig, Jonathan L., (2003), The Value of Knowledge and the Pursuit of Understanding, Cambridge: Cambridge University Press.

- McDowell, J. (1978). Are Moral Requirements Hypothetical Imperatives? in Proceedings of the Aristotelian Society, suppl. ser., 52.

- McDowell, J., (1995). Might There Be External Reasons? In J.E.J. Altham \& R. Harrison (eds.), World, Mind and Ethics: Essays on the Ethical Philosophy of Bernard Williams, Cambridge: Cambridge University Press, 68-85.

- Nagel, T., (1970). The Possibility of Altruism, Princeton: Princeton University Press; reprinted 1978.

- Nagel, T., (1970). The Possibility of Altruism, Princeton: Princeton University Press; reprinted 1978.

- Parfit, D., (2011). On What Matters, Oxford: Clarendon Press.

- Riggs, Wayne D., (2009). “Understanding, Knowledge, and the Meno Requirement”, in Haddock, Millar \& Pritchard 2009: 331-338 (Appendix D).

- Schroeder, M., (2007). Slaves of the Passions, New York: Oxford University Press.

- Setiya, Kieran. (2012). Introduction: Internal Reasons, in Kieran Setiya and Hille Paakkunainen (eds.) Internal Reasons: Contemporary Readings, Cambridge, MA: MIT Press, pp. 1-34. 
- Tresan, J. (2006). De dicto internalist cognitivism. Noûs 40: 143-65.

- Tresan, J. (2009b). The challenge of communal internalism. The Journal of Value Inquiry 43: 179-99.

- Velleman, J. D. (2000). The Possibility of Practical Reason, Oxford: Oxford University

Press.

- Williams, B., (1979). Internal and External Reasons, reprinted in Moral Luck, Cambridge: Cambridge University Press, 1981, 101-13.

- Williams, B., (1989). Internal Reasons and the Obscurity of Blame, reprinted in B. Williams, Making Sense of Humanity, Cambridge: Cambridge University Press, 1995: 35-45.

- Williams, B. (1995b). Reply to MacDowell, in Internal Reasons: contemporary readings, ed. Keiran Setiya, MIT press

Afroogh, Saleh. Contextual Reason and Rationality. Diss. 2019

Afroogh, Saleh (2019). Contextual Reason and Rationality. Master's thesis, Texas A\&M University. Available electronically from http : / /hdl .handle .net /1969.1/186349.

$\underline{10.13140 / R G .2 .2 .21462 .06726}$ 